\title{
Volumetric Determination of Medial Epicondyle and Lateral Epicondyle of Humerus in Male and Female Volleyball Players
}

\author{
By
Belgin BAMAÇ, PhD $^{1}$, Tuncay ÇOLAK, PhD $^{1}$, Aydin ÖZBEK, MD ${ }^{1}$, Nahit YENIGÜN ${ }^{2}$, Serap ÇOLAK ${ }^{2}$ and Yalin BAMAÇ ${ }^{1}$ \\ Department of Anatomy ${ }^{1}$, Kocaeli University Faculty of Medicine, Kocaeli, Turkey \\ School of Physical Education and Sport ${ }^{2}$, Kocaeli University, Kocaeli, Turkey
}

- Received for Publication, April 16, $2003-$

Key Words: Volleyball, Medial epicondyle, Lateral epicondyle, Cavalieri

\begin{abstract}
Summary: The aim of this study was to assess the volume of the medial epicondyle and lateral epicondyle in comparison with the distal end of humerus volume in male and female elite athletes participating in an impact loading sport (volleyball). The volleyball group consisted of 17 female, aged $20.47 \pm 2.47$ years (mean \pm SD), 16 male aged $21.68 \pm 3.47$ years (mean \pm SD); training for about 8 hours/week. The control group consisted of 15 nonactive females aged $21.73 \pm 2.68$ years (mean \pm SD) and 14 nonactive males aged $23.35 \pm 4.16$ years (mean \pm SD). Anthropometric determinations (height, weight, limb length, girth of arm and forearm) were made on each subjects. Range of motion was evaluated by standard goniometric technique. Comparative plain films of both elbows were obtained in an anteroposterior projection. The volumes of the medial epicondyle and lateral epicondyle were determined by the principle of Cavalieri which is an effective stereologic volume calculation method. In the volleyball players, increased medial epicondyle volume was recorded in the dominant and nondominant arms as compared with the control subjects $(P<0.05)$. Wrist flexors are highly involved in spiking, blocking and serving in volleyball. In this study we founded volume of medial epicondyle which is the connection point of flexor muscle was increased because of loading.
\end{abstract}

It is well known that adaptational processes following athletic training effect skeletal system, muscles and tendons of the athlete. Functional adaptation of the bone is shown by not only increase of bone mineral acquisition, but also changes in bone geometry and bigger bone ledges at the insertion of muscles and tendons. These adaptations most certainly can occur from overuse of the musculoskeletal system, as well as from intense participation in a specific sport or activity. Volleyball imposes the high impact and weight bearing load upon the axial and appendicular skeleton. In volleyball, high muscular forces act on the skeleton during smashing, serving and blocking.

Xia Qu Ma, investigated the effects of a variety of mechanical forces on human humerus morphology of swimmer, gymnasts, javelin throwers, discus throwers and weightlifters by measuring the cortical thickness and diameter of humerus at its proximal, middle and distal thirds from radiographs ${ }^{1}$. She suggest that in different events there are different directions of applied muscle force, so a range of stimuli are transmitted to the bone resulting in different speeds of growth, hence the cortex and overall diameters of the humerus, differ among the participants of different sports.

Previous studies have suggested that bone mineral content (BMC) and density (BMD) are significantly higher in athletes than in age-matched healthy non-athletic subjects ${ }^{2,3)}$. Alfredson et al. founded significantly higher BMD values of total body, lumbarspine, hip, dominant and nondominant humerus in volleyball players compared with the nonactives ${ }^{4)}$. It appears that in volleyball, the loading situations are associated with strains that evoke a great osteogenic stimulus. The difference in BMD of the humerus between the groups is more an expression of a higher general strain level for both arms in the volleyball group.

Functional adaptation of bone has been described by Feldmeier ${ }^{5)}$. He found an increase of bone thickness and growth of bone ledges at the 
insertion of muscles and tendons due to continuous mechanical stress.

In this study we wanted to examine whether the strain during smashing, blocking and serving leads to differences in the elbow region morphology of the male and female volleyball players. We evaluated the volume of the medial epicondyle and lateral epicondyle which is the connection points of forearm muscles, in the arms of volleyball players and nonactive control group on radiographs by Cavalieri's geometrical principle.

The purpose of this study was to learn whether there were any differences between volleyball players and control subjects with respect to volume of medial epicondyle and lateral epicondyle of humerus. The study was also designed to compare the side to side differences in dominant and nondominant arms of volleyball players.

\section{Materials and Methods}

The volleyball group consisted of 16 male volleyball players, aged $21.6 \pm 3.4$ years (mean \pm SD) and 17 female volleyball players, aged $20.4 \pm 2.4$ years (mean $\pm \mathrm{SD}$ ). They had been active in volleyball for 9 years and practised 8 hours/week. The control group consisted of 14 nonactive males, aged $23.3 \pm 4.1$ years (mean $\pm \mathrm{SD}$ ) and 15 nonactive females, aged $21.7 \pm 2.6$ years (mean \pm SD) randomly recruited among our university students, based on their age and physical activity history. They were not participating in any kind of regular or organized sport activity. All volleyball players and nonactive controls were in good health, on no medication known to affect bone metabolism and had no ongoing or previous (last year) injuries. All subjects were informed of the study procedure, purposes and known risks and all gave their informed consent.

Height and weight were measured under standardized conditions. A limited physical examination was carried out, measurements were made of range of motion of the joints of the upper extremity, girth of the arm and forearm and length of the limbs. We investigated girth of the forearm $10 \mathrm{~cm}$ proximal to the processus styloideus of ulna and girth of the arm $10 \mathrm{~cm}$ proximal to the medial epicondyle of humerus.

We measured the lenght of the upper limb as the distance between the acromial angle and the tip of the third digit of the hand, when the shoulder was flexed to 90 degrees with the elbow extended. Lower limb lenght was the distance between umbilicus and malleolus medialis of the foot.

Anteroposterior roentgenograms of both elbow were obtained from volleyball players and control subjects. Radiographs of all subjects were made by using Diamond $150 \mathrm{TH}$ model x-ray unit. Standardized procedure implemented by the same operator and instrument. The interpretation of each film was done by the same investigator. The upper limb was positioned at $90^{\circ}$ of supination with elbow extension and it was controlled during the radiographic procedure by the same investigator.

The volumes of the medial epicondyle and lateral epicondyle in comparison with the distal end of humerus volume, determined by Cavalieri's geometrical principle which is an effective stereologic volume calculation method. This method associated with point - counting volumetry was used to calculate the volume the structures found in bone. The volume of an organ or parts of it can be safely determined by the principle of Cavalieri according to Gundersen and Jensen ${ }^{6}$.

Silva and Merzel, determined the volume of the same rat lower incisors the hemimandible by Cavalieri's geometrical principle and by Archimede's principle. They didn't find any differences between the methods ${ }^{7)}$. Diab et al. calculated the volume of the normal and scoliotic vertebral bodies using Cavalieri's principle for irregular objects on radiographs and CT scans ${ }^{8}$. Then they compared the obtained values with values derived from serial CT scans. They concluded that the method is easy to apply and has satisfactory accuracy for in vivo longitudinal studies of the volume vertebral body on radiographs and CT scans.

We selected points of criteria in order to distinguish the medial epicondyle, lateral epicondyle and distal end of the humerus bone on the direct $\mathrm{x}$-rays of volleyball players and control subjects. First, we drew a longitudinal line down the long axis of the humerus bone. Then, we made a horizontal line from the peak of fossa olecrani, perpendicular to the long axis. We made another horizontal line ending the extreme points of capitulum humeri and trochlea humeri located at the bottom of humerus. Thus, we distinguished the humerus distal end. In order to separate medial epicondyle and lateral epicondyle from the humerus distal end, we drew another line from starting most lateral and medial points of fossa olecrani. So we separated medial epicondyle and lateral epicondyle from humerus distal end (Fig. 1). After that, we made point counting by randomly placing the measurement scale on the x-rays (Fig. 2). We repeated this counting three times. Then we calculated the actual value by taking average of these three numbers. We substituted the numbers in the formula used for volume calculations. The volume formula is $\mathrm{V}=\sum \mathrm{P} . \mathrm{A}(\mathrm{P}) . \mathrm{T}$, where $\mathrm{V}$ is volume, $\sum \mathrm{P}$ is the total number of points 


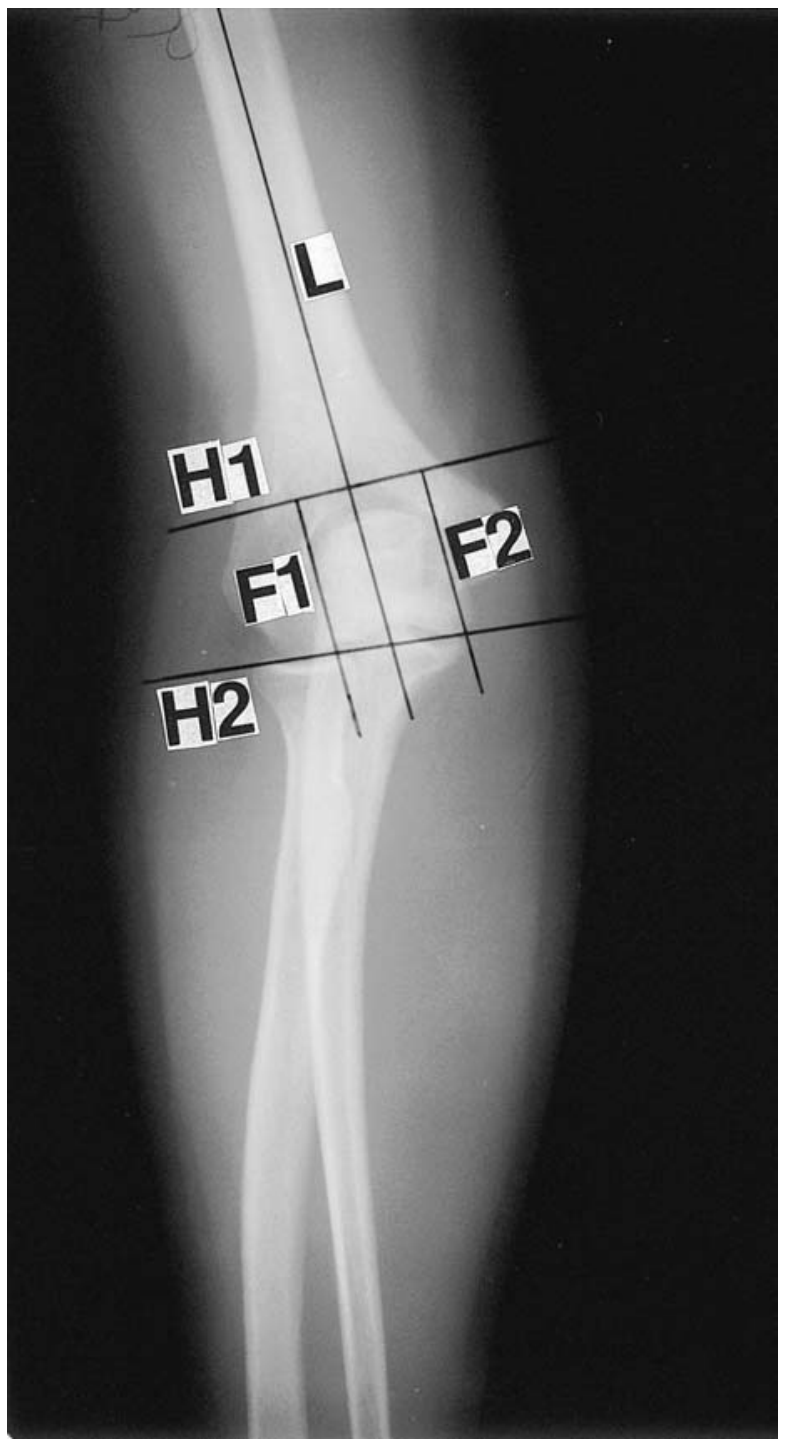

Fig. 1. Separation medial and lateral epicondyle from the humerus distal end. L: longitudinal line down the long axis of the humerus, H1: horizontal line from the peak of fossa olecrani perpendicular to the long axis, $\mathrm{H} 2$ : horizontal line ending the extreme points of capitulum humeri and trochlea humeri, F1: line from starting most lateral point of fossa olecrani, F2: line from starting most medial point of fossa olecrani.

on the sections, $\mathrm{A}(\mathrm{P})$ is the area represented by a point and $\mathrm{T}$ is the section thickness.

$\mathrm{V}($ Volume of distal humerus $)=\sum \mathrm{P}$ (Number ofpoints on distal humerus). A(P). $T$

$\mathrm{V}($ Volume of epicondyle $)=\sum \mathrm{P}($ Number ofpoints on epicondyle). A(P). $T$

When we compared the formulas, $\mathrm{A}(\mathrm{P})$ and $\mathrm{T}$ are eliminated because these values were obtained

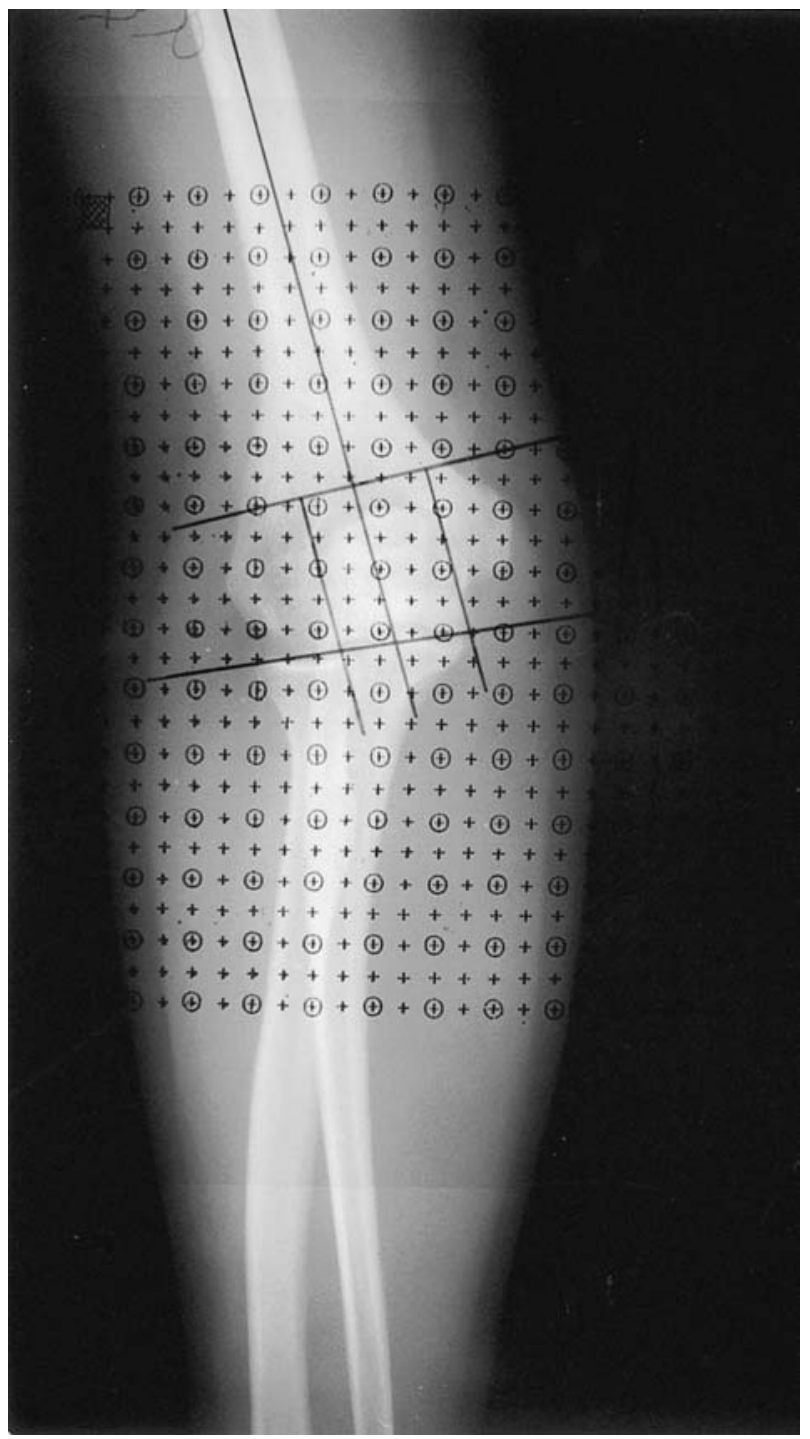

Fig. 2. Point counting by randomly placing the measurement scale on the x-ray.

from same structure. The remaining proportion of volumes shall give us proportion of the points. The important thing for us was the ratio of the numbers of points in the dimention. We explained the results as unit without any numerical value.

The study was conducted according to the guidelines of the Decleration of Helsinki and approved by the ethics committee of our faculty.

\section{Results}

Group characteristics are shown in Table 1. There were not significant differences among groups for age, weight, arm and forearm circumference. 
Table 1. Characteristics of the volleyball players and control groups

\begin{tabular}{lcrrrrr}
\hline & $\begin{array}{c}\text { Volleyball players } \\
\text { (female) } \mathrm{n}=17\end{array}$ & $\begin{array}{c}\text { Control group } \\
\text { (female) } \mathrm{n}=15\end{array}$ & $\mathrm{P}$ & $\begin{array}{c}\text { Volleyball players } \\
\text { (male) } \mathrm{n}=16\end{array}$ & $\begin{array}{l}\text { Control group } \\
(\mathrm{male}) \mathrm{n}=14\end{array}$ & $\mathrm{P}$ \\
\hline Age (yrs) & $20.4 \pm 2.4$ & $21.2 \pm 2.6$ & 0.177 & $21.6 \pm 3.4$ & $23.3 \pm 4.1$ & 0.241 \\
Height (cm) & $174.0 \pm 7.6$ & $164.2 \pm 5.5$ & $\mathbf{0 . 0 0 0}$ & $186.6 \pm 9.0$ & $176.6 \pm 7.8$ & $\mathbf{0 . 0 0 3}$ \\
Weight (kg) & $61.1 \pm 8.7$ & $59.0 \pm 8.8$ & 0.504 & $75.5 \pm 8.4$ & $70.7 \pm 8.6$ & 0.142 \\
Lenght of upper extremity (cm) & $73.3 \pm 5.2$ & $69.16 \pm 3.9$ & $\mathbf{0 . 0 1 8}$ & $79.1 \pm 3.3$ & $77.2 \pm 3.9$ & 0.178 \\
Lenght of lower extremity (cm) & $95.9 \pm 6.0$ & $91.6 \pm 2.3$ & $\mathbf{0 . 0 1 4}$ & $101.1 \pm 5.6$ & $97.8 \pm 5.0$ & 0.105 \\
Girth of forearm (cm) & $20.8 \pm 1.62$ & $20.6 \pm 0.9$ & 0.597 & $22.7 \pm 1.8$ & $22.0 \pm 1.4$ & 0.253 \\
Girth of arm (cm) & $25.20 \pm 1.8$ & $24.94 \pm 2.0$ & 0.711 & $27.5 \pm 1.7$ & $23.00 \pm 2.0$ & 0.480 \\
\hline
\end{tabular}

Values are given as mean \pm SD. Significant P-values highlighted.

Table 2. Range of motion of upper extremity (Goniometric degree)

\begin{tabular}{lcccccc}
\hline & $\begin{array}{c}\text { Volleyball players } \\
\text { (female) } \mathrm{n}=17\end{array}$ & $\begin{array}{c}\text { Control group } \\
\text { (female) } \mathrm{n}=15\end{array}$ & $\mathrm{P}$ & $\begin{array}{c}\text { Volleyball players } \\
\text { (male) } \mathrm{n}=16\end{array}$ & $\begin{array}{c}\text { Control group } \\
(\mathrm{male}) \mathrm{n}=14\end{array}$ & $\mathrm{P}$ \\
\hline Shoulder flexion & $180.0 \pm 0.0$ & $180.0 \pm 0.0$ & 1.000 & $180.6 \pm 2.5$ & $180.0 \pm 0.0$ & 0.350 \\
Shoulder hyperextension & $55.0 \pm 6.1$ & $44.3 \pm 4.1$ & $\mathbf{0 . 0 0 0}$ & $53.6 \pm 9.3$ & $43.5 \pm 4.5$ & $\mathbf{0 . 0 0 1}$ \\
Shoulder abduction & $180.5 \pm 2.4$ & $180.0 \pm 0.0$ & 0.348 & $180.6 \pm 2.5$ & $180.0 \pm 0.0$ & 0.350 \\
Shoulder hyperadduction & $45.0 \pm 7.7$ & $41.0 \pm 3.8$ & 0.07 & $50.0 \pm 12.2$ & $42.8 \pm 3.7$ & 0.085 \\
Shoulder internal rotation & $95.5 \pm 7.6$ & $88.6 \pm 2.9$ & $\mathbf{0 . 0 0 1}$ & $91.4 \pm 10.5$ & $89.2 \pm 2.6$ & 0.206 \\
Shoulder external rotation & $96.7 \pm 6.6$ & $89.3 \pm 3.1$ & $\mathbf{0 . 0 0 0}$ & $91.3 \pm 10.4$ & $90.0 \pm 1.9$ & 0.106 \\
Elbow flexion & $145.8 \pm 5.3$ & $143.0 \pm 4.5$ & 0.195 & $146.1 \pm 6.0$ & $143.9 \pm 4.4$ & 0.283 \\
Forearm supination & $91.1 \pm 3.3$ & $89 \pm 3.8$ & 0.179 & $91.5 \pm 5.0$ & $87.5 \pm 3.2$ & $\mathbf{0 . 0 0 8}$ \\
Forearm pronation & $92.0 \pm 3.0$ & $88.6 \pm 2.9$ & $\mathbf{0 . 0 0 3}$ & $89.6 \pm 1.3$ & $88.7 \pm 2.2$ & 0.198 \\
Wrist flexion & $90.0 \pm 0.0$ & $89.3 \pm 1.7$ & 0.126 & $88.2 \pm 3.7$ & $82.6 \pm 11.8$ & 0.323 \\
Wrist extension & $78.8 \pm 9.7$ & $68.6 \pm 4.8$ & $\mathbf{0 . 0 0 2}$ & $74.3 \pm 10.5$ & $68.5 \pm 5.3$ & 0.73 \\
Wrist ulnar deviation & $57.9 \pm 8.6$ & $46.3 \pm 11.0$ & $\mathbf{0 . 0 0 2}$ & $47.5 \pm 7.2$ & $43.0 \pm 9.5$ & 0.162 \\
Wrist radial deviation & $36.4 \pm 6.7$ & $23.6 \pm 6.9$ & $\mathbf{0 . 0 0 0}$ & $29.8 \pm 2.9$ & $24.6 \pm 5.3$ & $\mathbf{0 . 0 0 4}$ \\
\hline
\end{tabular}

Values are given as mean \pm SD. Significant P-values highlighted.

Volleyball players were taller than the control subjects. Upper and lower limb lenghts of the female volleyball players were significantly longer than control subjects. Range of motion values of upper extremity are shown in Table 2 . In the female volleyball players goniometric degrees were clearly increased. As a result of goniometric measurements, there were significant differences in internal rotation, external rotation and hyperextension degrees of shoulder, radial deviation, ulnar deviation and extension degrees of wrist and pronation degree of forearm between female volleyball players and control subjects. In the male volleyball players hyperextension of shoulder, radial deviation of wrist and supination of forearm degrees were significantly different from control subjects. These values were greater in the male volleyball players.

In this study there was significant difference between volleyball players and control subjects with respect to volume of medial epicondyle in comparison with the distal end of humerus volume in the dominant and nondominant arms. The difference was observed in male as well as female subjects. We observed the volume of lateral epicondyle increased in comparison with the distal end of humerus volume in the male and female volleyball players in both arms (Table 3). But it was not significant. There was no significant difference between dominant and nondominant arms regarding volume of medial epicondyle and lateral epicondyle in both male and female volleyball players (Table 4). The visual inspection of the radiographs suggest no obvious difference in bone structure between the dominant arm and the contralateral arm for the volleyball players. As a result of this study we found that the volume of medial epicondyle increased in volleyball players compared with the nonactive subjects.

The results are presented as means \pm SD. Differences between the groups were calculated using a non parametric tests for independent samples (Mann Whitney-u). The SPSS package for Personal Computer was used for the statistical analyses. A P value less than 0.05 was considered significant. 
Table 3. The ratio of the volume of lateral epicondyle and medial epicondyle to the volume of distal end of humerus values for volleyball players and control groups

\begin{tabular}{lcccccc}
\hline & $\begin{array}{c}\text { Volleyball } \\
\text { players } \\
\text { (female) } \\
\mathrm{n}=17\end{array}$ & $\begin{array}{c}\text { Control } \\
\text { group } \\
\text { (female) } \\
\mathrm{n}=15\end{array}$ & $\mathrm{P}$ & $\begin{array}{c}\text { Volleyball } \\
\text { players } \\
\text { (male) } \\
\mathrm{n}=16\end{array}$ & $\begin{array}{c}\text { Control } \\
\text { group } \\
\text { (male) } \\
\mathrm{n}=14\end{array}$ & $\mathrm{P}$ \\
\hline $\begin{array}{l}\text { The ratio of the volume of lateral } \\
\text { epicondyle to the volume of distal } \\
\text { end of humerus (dominant) }\end{array}$ & $3.1 \pm 0.3$ & $3.3 \pm 0.3$ & 0.104 & $3.1 \pm 0.3$ & $3.4 \pm 0.5$ & 0.058 \\
$\begin{array}{l}\text { The ratio of the volume of lateral } \\
\text { epicondyle to the volume of distal } \\
\text { end of humerus (nondominant) }\end{array}$ & $3.2 \pm 0.4$ & $3.51 \pm 0.5$ & 0.095 & $3.107 \pm 0.3$ & $3.3 \pm 0.3$ & 0.080 \\
$\begin{array}{l}\text { The ratio of the volume of medial } \\
\text { epicondyle to the volume of distal } \\
\text { end of humerus (dominant) } \\
\begin{array}{l}\text { The ratio of the volume of medial } \\
\text { epicondyle to the volume of distal } \\
\text { end of humerus (nondominant) }\end{array}\end{array}$ & $4.3 \pm 0.9$ & $5.3 \pm 0.9$ & $\mathbf{0 . 0 0 6}$ & $3.8 \pm 0.6$ & $4.4 \pm 0.5$ & $\mathbf{0 . 0 1 2}$ \\
\hline
\end{tabular}

Values are given as mean \pm SD. Significant P-values highlighted.

Table 4. The ratio of the volume of lateral epicondyle and medial epicondyle to the volume of distal end of humerus values for volleyball players in dominant and nondominant arms

\begin{tabular}{|c|c|c|c|c|c|c|}
\hline & \multicolumn{3}{|c|}{ Female Volleyball Players $n=17$} & \multicolumn{3}{|c|}{ Male Volleyball Players $n=16$} \\
\hline & $\begin{array}{l}\text { Dominant } \\
\text { arm }\end{array}$ & $\begin{array}{c}\text { Nondominant } \\
\text { arm }\end{array}$ & $\mathrm{P}$ & $\begin{array}{l}\text { Dominant } \\
\text { arm }\end{array}$ & $\begin{array}{c}\text { Nondominant } \\
\text { arm }\end{array}$ & $\mathrm{P}$ \\
\hline $\begin{array}{l}\text { The ratio of the volume of lateral } \\
\text { epicondyle to the volume of } \\
\text { distal end of humerus }\end{array}$ & $3.1 \pm 0.3$ & $3.2 \pm 0.4$ & 0.738 & $3.1 \pm 0.3$ & $3.1 \pm 0.3$ & 0.859 \\
\hline $\begin{array}{l}\text { The ratio of the volume of } \\
\text { medial epicondyle to the volume } \\
\text { of distal end of humerus }\end{array}$ & $4.3 \pm 0.9$ & $4.6 \pm 0.9$ & 0.134 & $3.8 \pm 0.6$ & $3.8 \pm 0.8$ & 0.962 \\
\hline
\end{tabular}

\section{Discussion}

Exercise may exert a very local effect on the stressed parts of the skeleton. Different sports may load the skeleton at various sites, in different ways. The site-spesific response of the skeleton seems to be induced by the specific loading pattern of the sport $^{9}$. Studies of athletes in different sports may explain possible relationships between their specific activity and bone mass. In the study by Alfredson et al., young female volleyball players had a high bone mass ${ }^{4}$. The demonstrated high bone mass seemed to be related to the type of loading subjected to each BMD site. In tennis and squash players it has been shown that the humerus adapts to the loads applied to it ${ }^{10,11)}$. In a study of Creighton et al. women who participate in impact sports such as volleyball and basketball had higher BMD and bone formation values than female swimmers ${ }^{12}$. They suggest that high strain rates are more effective at inducing new bone formation and enhancing BMD at weight-bearing sites. The increased $\mathrm{BMC}$ and $\mathrm{BMD}$ in volleyball players probably reflect bone adaptation to the extreme forces acting upon the skeleton during playing volleyball.

The aim of our study was to investigate whether overuse of forearm muscles associated with spiking and serving in volleyball was related to skeletal differences in the humerus which is the connection point of these muscles. In this study there was significant difference between volleyball players and control subjects with respect to volume of medial epicondyle in the dominant and nondominant arms. The differences can possibly be related to the strains created by muscles and tendons upon skeleton when playing volleyball. It's difficult to compare our results with other studies due to differences in methods. The difference between this study and the others is that while we measured bone volume, the 
other studies measured bone mineral content and bone mineral density. Volume, BMC and BMD are factors that support each other.

The observed differences in volume of medial epicondyle can be related to the type of loading the skeleton undergoes when playing volleyball. Volleyball needs a strong flexion of the hand and wrist flexors are highly involved in volleyball. This high involvement throughout play may result in overload of this muscular group. On the other hand, the elbow is subjected to enormous valgus stresses during throwing motion. Valgus stress, from throwing causes increased forces to the medial elbow in the volleyball. The primary dynamic stabilizer of this stress is the flexor-pronator muscle mass ${ }^{13)}$. The flexor-pronator muscle group has its common tendon of origin at the medial epicondyle. Continuous mechanical stress results growth of the bone ledges at the insertion of muscles, and frequent develepment of bony spurs at the insertion of tendons ${ }^{4,14}$. We suggest that the volume of medial epicondyle which is the connection point of wrist flexor muscles increased in volleyball players because of loading. Our results are in accordance with those of previous studies that have shown bony hypertrophy in response to exercise. Todorov, examined 54 tennis players. He confirmed the thickening of the opaque substance both by the periosteal and medullary pathways ${ }^{15)}$. Hypertrophy of the humerus is distributed irregularly the length of the bone and is more pronounced in the distal part of the bone than in the proximal part. Gore et al. reviewed the acute and chronic diffuse and localized manifestations of sports-related stress at the elbow in 29 symptomatic professional, amateur and adolescent athletes ${ }^{16)}$. They observed, generalized bony hypertrophy manifested by thickening of the cortex of the humeral shaft, medial epicondyle, olecranon and ulnar groove in 18 of 20 professional adult athletes and 15 of 16 professional pitchers. On the other hand, our results compare well with Toriola et al. who showed that basketball players and volleyball players had wider humerus bi-epicondyler diameter than the nonathletes. They found that the humerus bi-epicondyler diameter of basketball players was significantly wider than volleyball players and nonathletes ${ }^{17)}$. They suggested that the differences observed between the athletic groups were related to the morphological factors which influence the basic components of competitive sports performance.

Hyperemia of the constantly strained extremity and mechanical stimulation can change bone structure and size. If the mechanical stimulus to a bone is increased repetitively, additional bone tissue will be deposited. Lanyon and Hartman suggested that bending or loading of a bone caused transient electric potential differences across the bone which act as pulsed electric fields that induce bone cell activity, leading to increased bone deposition at points of compressional stress ${ }^{18}$. In this study it is seems that in the volleyball group the strain during smashing, blocking and serving seems to be high enough to promote bone formation in the dominant and nondominat medial epicondyle. The high muscular force that stresses the medial epicondyle is the most probable reason for the increased medial epicondyle volume in volleyball players.

In this study there was no significant difference between dominant and nondominant arms regarding volume of medial epicondyle and lateral epicondyle in both male and female volleyball players. This can probably be explained by the fact that the nondominant arm is used as much as dominant arm in volleyball and takes the great load during blocking and weight-bearing activities. It must be taken into account that professional volleyball players perform much weightlifting involving the upper limbs and consequently, some degree of adaptation would also be expected to take place in the nondominant $\mathrm{arm}^{2}$. As a contrast, Lee et al. found a significantly higher BMD in the dominant whole arm in the volleyball players ${ }^{19)}$. Alfredson et al. concluded that the loading on the dominant spiking and serving arm was associated with a higher bone mass in the humerus in female volleyball players ${ }^{20)}$. However, in the study by Haapasalo et al. BMD was measured in the distal radius and compared with the volleyball players, side to side difference was higher in squash players ${ }^{21}$. It seems that the side to side differences in both humerus and distal radius are larger in squash and tennis players than in volleyball players. This could be explained by the nature of the sports. When playing squash and tennis, the impact forces are probably higher, repeated more often and therefore produce higher strains on the skeleton in the dominant arm.

We found significantly differences between female volleyball players and control subjects with respect to range of motion of upper extremity. In Turkey, women have not opportunity for participation of any sport or recreation activity as much as men. This may explain the reason of the differences.

Different kinds of physical activity induced the specific changes in skeletal regions. This study showed that volleyball induced the specific changes in the medial epicondyle of humerus. The differences can possibly be related to the strains created when playing volleyball.

Retrospective studies indicate that adaptations occur in muscles, tendons and bones in response to high training loads, and these particular adaptations 
are not beneficial to performance and may be associated with increased injury risk ${ }^{22}$. In order to understand the spectrum of sports related elbow injuries, it is necessary to define the anatomic parameters that will cause overtraining. Because different anatomical variations may be acting to cause the clinical presentation of injuries. The physician has to know how the athlete's body will react to high loads of training. Volleyball is a physically demanding sport so the player's musculoskeletal base is important. Volleyball can repetitively stress the hand, wrist, elbow and shoulder. The volleyball players are often exposed to chronic valgus stresses which causes increased forces to the medial elbow. We have suggested that it is very important to define the elbow region morphology of volleyball players in order to identify the possible pathologies in subclinic condition.

\section{References}

1) Xia Qu Ma. Morphological effects of mechanical forces on the human humerus. Br J Sp Med 1992; 26(1).

2) Calbet JAL, Herrera PD and Rodriguez LP. High bone mineral density in male elite professional volleyball players. Osteoporos Int 1999; 10:468-474.

3) Haapasalo H, Kontulainen S, Sievanen H, Kannus P, Jarvinen $\mathrm{M}$ and Vuori I. Exercise-induced bone gain is due to enlargement in bone size without a change in volumetric bone density: A peripheral quantitative computed tomography study of the upper arms of male tennis players. Bone 2000; 27:351-357.

4) Alfredson $H$, Nordström $P$ and Lorentzon R. Bone mass in female volleyball players: A comparison of total and regional bone mass in female volleyball players and nonactive females. Calcif Tissue Int 1997; 60:338-342.

5) Feldmeier C. Grundlagen der Sporttraumatologie. München, Zenon Medizin - Verlag 1998; 71-88.

6) Gundersen HJG and Jensen EB. The efficiency of systematic sampling in stereology and its prediction. J Microscopy 1987; 147(3):229-263.

7) Silva MA and Merzel J. Stereological determination of the volume of the rat hemimandible tissues. Anat Rec 2001; Jul 1: 263(3):255-9.
8) Diab KM, Ollmar S, Sevastik JA, Willers U and Svensson A. Volumetric determination of normal and scoliotic vertebral bodies. Eur Spine J 1998; 7(4):282-87.

9) Alfredson $H$, Nordström $P$ and Lorentzon R. Total and regional bone mass in female soccer players. Calcif Tissue Int 1996; 59:438-442.

10) Jones HH, Priest JD, Hayes WC, Tichenor CC and Nagel DA. Humeral hypertrophy in response to exercise. J Bone Joint Surg 1977; 59-A:204-208.

11) Haapasalo H, Sievanen H, Kannus P, Heinonen A, Oja P and Vuori I. Dimensions and estimated mechanical characteristics of the humerus after long-term tennis loading. J Bone Miner Res 1996; 11(6):864-72.

12) Creighton DL, Morgan AL, Boardley D and Brolinson PG. Weight-bearing exercise and markers of bone turnover in female athletes. J Appl Physiol 2001; 90:565-570.

13) Safran MR. Elbow injuries in athletes. Clin Orthop Rel Res 1995; 310:257-77.

14) Krahl H, Michaelis U, Pieper HG, Quack G and Montag M. Stimulation of bone growth through sports. The American Journal of Sports Medicine 1994; 22-6:751-757.

15) Todorov T. Tennis de haut niveau: modifications osseouses et articularies du membre superior actif du joneur. Ann ENSEPS 1975; 8:21-26.

16) Gore RM, Rogers LF, Bowerman J, Suker J and Compere CL. Osseous manifestations of elbow stress associated with sports activities. AJR 1980; 134:971-977.

17) Toriola AL, Adeniran SA and Ogunremi PT. Body composition and anthropometric characteristics of elite male basketball and volleyball players. J Sports Med 1987; 27:235-39.

18) Lanyon LE and Hartman W. Strain related electrical potentials recorded in vitro and in vivo. Calcif Tissue Res 1977; 22:315-327.

19) Lee EJ, Long KA, Risser WL, Poindexter HB, Gibbons WE and Goldzieher J. Med Sci Sports Exerc 1995; Oct; 27(10):1354-61.

20) Alfredson $H$, Nordström $P$, Pietila $T$ and Lorentzon R. Long-term loading and regional bone mass of the arm in female volleyball players, Calcif Tissue İnt 1998; 62:303308.

21) Haapasalo H, Kannus $P$, Sievanen $H$, Heinonen A, Oja P and Vuori I. Long-term unilateral loading and bone mineral density and content in female squash players. Calcif Tissue Int 1994; 54(4):249-55.

22) Kibler WB, Chandler TJ and Stracener ES. Musculoskeletal adaptations and injuries due to overtraining. Exerc Sport Sci Rev 1992; 20P:99-126. 